Chapter 13

\title{
Water Treatment for Centre and Home-Based Haemodialysis
}

\author{
Shyam Dheda, Carolyn Van Eps, Carmel Hawley and \\ David W. Johnson
}

Additional information is available at the end of the chapter

http://dx.doi.org/10.5772/59380

\section{Introduction}

The process of haemodialysis is mirrored on the physiological principles of the kidney. Specifically the process of diffusion, where blood is made to flow in a counter current to the direction of dialysis fluid and ultrafiltration, where fluid is pressured across a semi permeable membrane using a convective force.

A large quantity of high purity dialysis water is required to safely perform a dialysis treatment. A single 4-hour dialysis treatment can require up to 150L of dialysis quality "ultra pure" water. Producing this high quality water is a multi step filtration process requiring several levels of processing before it is of a sufficient quality to be presented to the dialyser membrane and the patient's blood. Depending on the quality of the source water, the production of this 150L of dialysis quality water, can require the processing of up to 1000L of drinking quality water. This results in between $60-90 \%$ of source water being rejected to waste.

Ideally pure water used for dialysis should contain no contaminants eg. particles, trace elements, chemicals, organic matter, bacteria or bacterial fragments. Since this water is in direct contact with the blood stream any impurities in the dialysis water has the potential to pass to the patient. Published accepted standards of water quality do exist and specify the minimum concentrations of contaminants that are allowed, bearing in mind that absolute purity is impossible and is often limited by testing thresholds.

Several contamination incidents, some fatal have been described in the literature where patients have inadvertently been exposed to contaminants due to a breakdown in the water purification process. Historical examples include fatal haemolysis from chlorine exposure, bone disease and dementia from aluminium exposure and fatal bacterial contamination 
resulting in liver failure [1-3]. There is also evidence that bacteria and bacterial fragments especially gram-negative lipopolysaccharide can induce an inflammatory state contributing to erythropoietin resistance, hypotension and a poor nutritional status [4].

Ultrapure water has more stringent microbiological criteria than standard dialysis water and has become the standard in most dialysis units. This is particularly relevant when considering the increasing use of on-line haemodiafiltration, which necessitates large volumes of ultrapure replacement fluid to be infused directly into the patient bloodstream, without the traditional barrier protection of the dialyser membrane. In addition the use of high flux dialyser membranes, theoretically may also allow bacterial fragments to cross into the blood compartment hence further necessitating the need for stringent water standards. Use of ultrapure water is associated with improvement in inflammatory and nutritional markers as well as anaemia and can be produced safely [4-6].

In the home setting much training, education and preparation is necessary prior to a patient safely performing dialysis at home and in turn this is also important with regards to water quality. Patient factors such as dexterity, visual acuity, hygiene, desire to be independent and ability to follow protocols are important. Importantly in the home setting, patients must correctly perform their own chlorine testing, equipment maintenance and WRO disinfection.

This chapter will discuss the various components of the water purification process required for haemodialysis both in the home and in dialysis units. We will also discuss the components of water quality testing and international standards. Finally, with the increasing constraints on water supply, there is a growing awareness of the need for, so called 'green dialysis units', where water conservation practices are utilised.

\section{Water source}

The quality of the feedwater must be appreciated when setting up a purification system for dialysis, either in a home or an in-centre setting. On a basic level, the lower the concentrations of contaminants the less elaborate the purification system. For instance, the size, number and types of filters necessary for a water purification installation in an inner city suburb with good quality piped water would be different from those for a rural setting with borehole water. Even within the same city and despite similar purification steps there is a considerable difference in the organic and inorganic substances in municipal water due to the difference in the origin of the water. This can be due to geology in the area of the source water (e.g. high iron or clay content), and local industry or farming practice (e.g. pesticide use or heavy metal contamination) in the area.

Rainwater collection tanks are commonly in use in many rural and remote Australian areas. However, this water can also have both microbiological and inorganic contaminants present, due to the roofing materials used and wildlife that have access to the roof (e.g. birds and possums). In one study of 27 households in Brisbane using rainwater tanks, $63 \%$ of tank water samples tested positive for E Coli and 78\% tested positive for enterococci. [7] 
Municipal water is primarily sourced from 2 areas, surface water and groundwater. Groundwater includes wells, aquifers and springs. They have less organic materials but higher inorganic ions eg. metals. Surface water, incudes lakes, ponds and rivers and have more organic matter, microbes and contaminants (eg pesticide, sewerage)

There are several processes involved in converting source water to drinking water standard. These include:

- Sedimentation, by which large particles are allowed to settle

- Flocculation where particles that remain suspended are removed by adding a coagulant (e.g. aluminium or iron sulphates) to form larger complexes called flocs, which are then removed, through a process of filtration and adsorption

- Softening: where calcium and magnesium salts are removed

- Oxidation and disinfection: is most commonly achieved with the addition of chlorine.

- Carbon filtration: the water is finally passed through a carbon filter to remove any remaining chemicals.

\begin{tabular}{llll}
\hline Type: & Ground water & Surface water & Rainwater \\
\hline Example: & Wells, springs & Lakes, ponds, rivers & Rooftop \\
\hline $\begin{array}{l}\text { Inorganic ions eg metals } \\
\text { Organic material eg }\end{array}$ & Less & Normal & Variable (dependent of roof construction) \\
\hline \begin{tabular}{l} 
bacteria, pesticides \\
\hline
\end{tabular} & & High & Present, variable \\
\hline
\end{tabular}

Table 1. Types of source water

Several instances in the literature highlight the unfortunate morbidity experienced by patients due to a failure to recognize the importance of knowing the source and nature of feed water used for dialysis. One such incident occurred in Brazil in 1996 where 26 patients died from acute liver failure following failure to recognize that the water supply was not being chlorinated. This led to poisoning by bacterial cyanotoxins, which are highly hepatotoxic. [8]

\section{Components of the water system}

Improving water quality to a standard required for safe haemodialysis utilises a step wise, water filtration process. Each component is specially designed to remove certain contaminants and is arranged in a manner so as to protect and increase the efficiency of the downstream components (Figure 1). For example, carbon filters efficiently remove chlorine, which is not removed by water reverse osmosis (WRO) and can damage WRO membranes, thereby reducing their efficiency. 


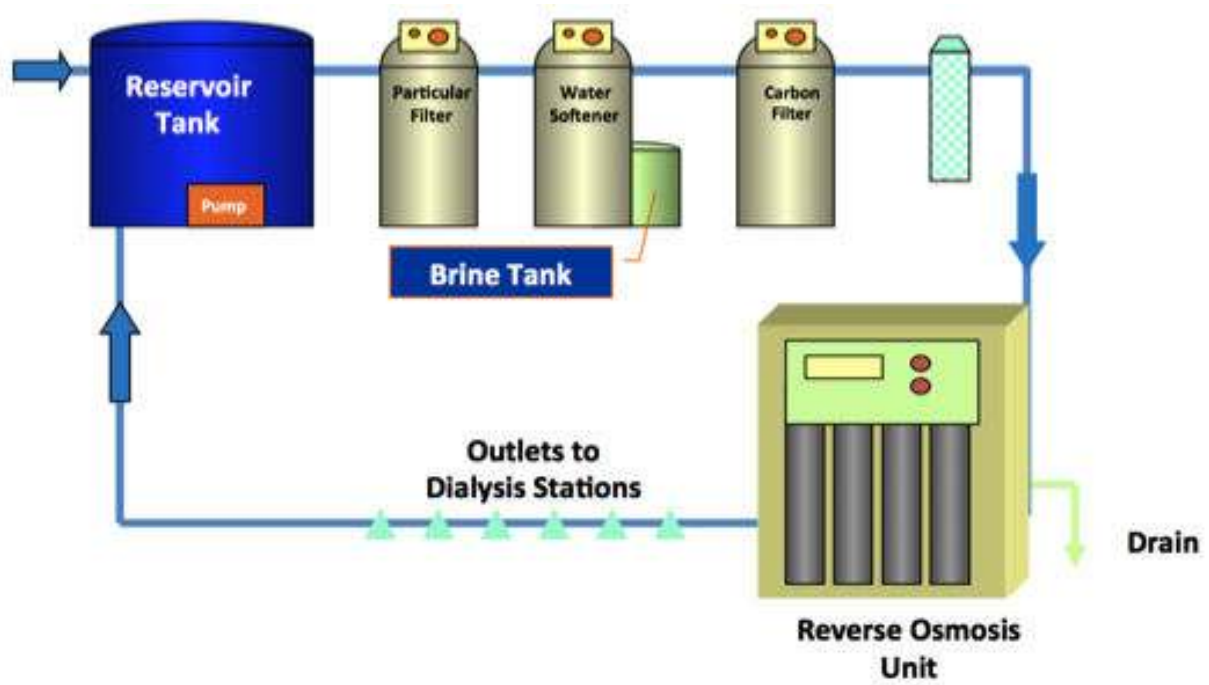

Figure courtesy of Fresenius Medical Care (C) Australia Pty Ltd. A typical dialysis water treatment setup consists of a reservoir tank, particle filters (multimedia, micron, bag filters), a water softener and 2 carbon tanks in series.

Figure 1. Schematic representation of a typical dialysis water treatment circuit

In centre dialysis units supplying multiple dialysis machines, which are used up to thrice a day, require large amounts of dialysis water and hence more involved filtration systems. However, even though home haemodialysis setups supply only one machine, they also are used in different feedwater settings, which may require minor changes in the type and size of filters (Figure 2).

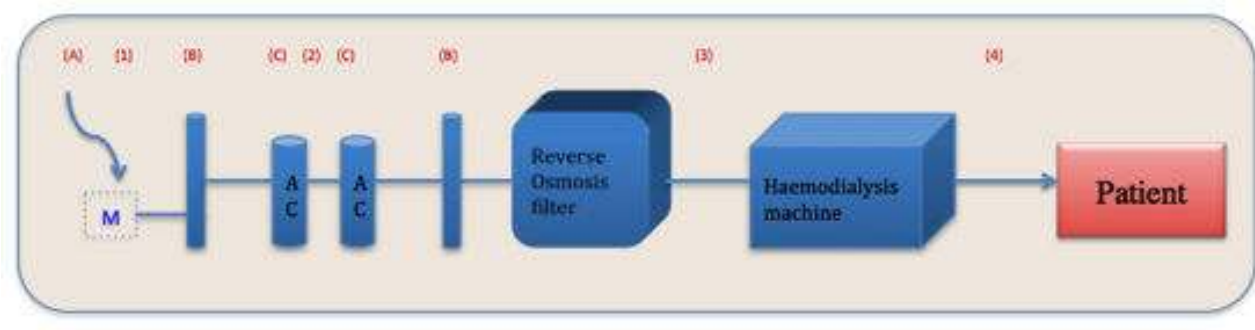

\section{M-Merlin reverse osmosis filter \\ 2. AC-activated carbon}

(A) The Cartridge unit is an easily changed, optional unit sometimes used to "pre treat" the source water. (B) micron particle filters, usually either $5 \mathrm{u}$ and $1 \mathrm{u}$ size, (C) activated carbon tanks

Figure 2. Schematic of home water treatment setup 


\subsection{Micron filters}

Water contains particulate matter, which may include sand, clay, silt, or colloidal matter. This particle load can be quantified by calculating the silt density index, which measures the time taken for a $0.45 \mu \mathrm{m}$ filter to experience a reduction in flow. These filters function to exclude particles on the basis of size and prevent fouling of the RO membrane (Figure 3). They are located both pre and post carbon filters. In addition the post carbon filter also traps any carbon flecks that may pass out of the carbon tanks.

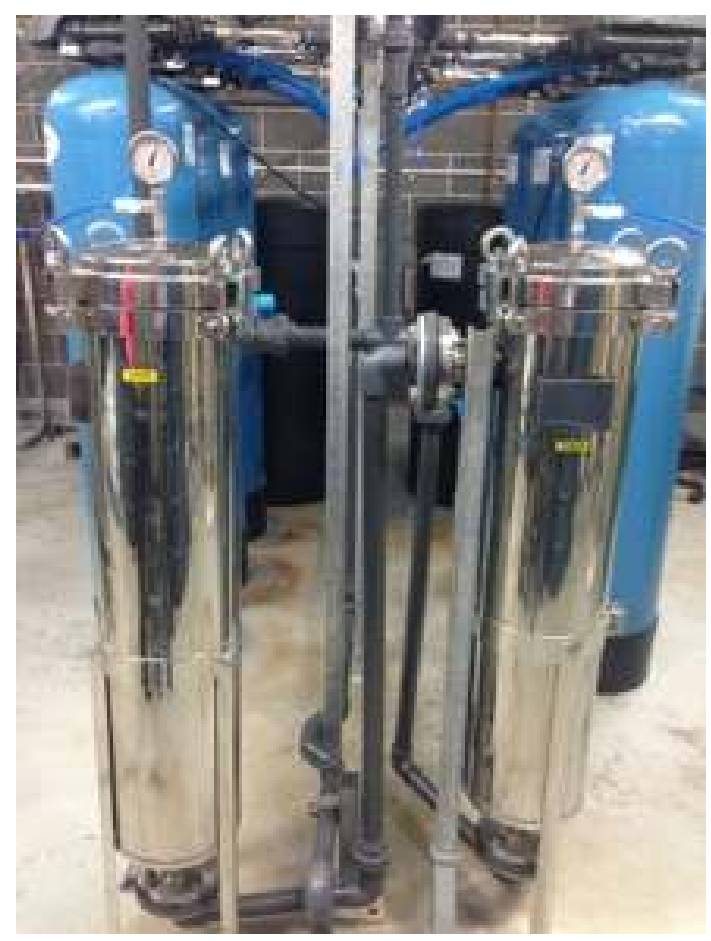

These micron filters are of a woven bag structure. Water passes through the filters in series, the $1^{\text {st }}$ a $25 \mathrm{u}$ and the second $10 \mathrm{u}$. They are changed every 4 weeks. Note the pressure gauges. The pressure differential between the $1^{\text {st }}$ filter (inlet) and the gauge on the softener (outlet, not Figured here) is closely monitored. The pressure differential slowly rises as the filter integrity drops.

Figure 3. Micron particle filters (bag filters)

For home dialysis, typically, a 10 -inch $1 \mu \mathrm{m}$ filter would be used but larger capacity e.g. 20 inch may be necessary in some areas with significant particle load such as areas with high clay concentrations. The International Organization for Standardization (ISO) recommends changing these according to the manufacturers specifications or using a change in pressure test, across the filter to check its integrity [9]. Common practice is to change these on schedule every two to four weeks. 


\subsection{Softener and multimedia filter}

Dissolved salts within in the water contribute to the hardness of water, which can cause 'hard deposits' and can foul the downstream WRO filter. Softeners function to reduce this hardness by removing the salts, commonly calcium and magnesium, by passing water through a resin, exchanging them for sodium (Figure 4). The ISO guidelines recommend a softener be used where feed water has hardness in excess of 10 GPG (grains/gallon) [9]. The softener is 'regenerated' by backwashing it with a high salt solution from the brine tank, effectively stripping the resin of bound calcium and magnesium salts. This can be set to a required time or volume schedule. Typically the softener is replaced every $3-5$ yrs. Multimedia filters are composed of multiple layers of media, typically coal, sand and garnet, which are of differing sizes. As water passes through the filter, particles up to $10 \mu \mathrm{m}$, suspended in the water are removed. Some units do not use multi-media filter, opting rather for the micron filters, which are cheaper and easier to replace.

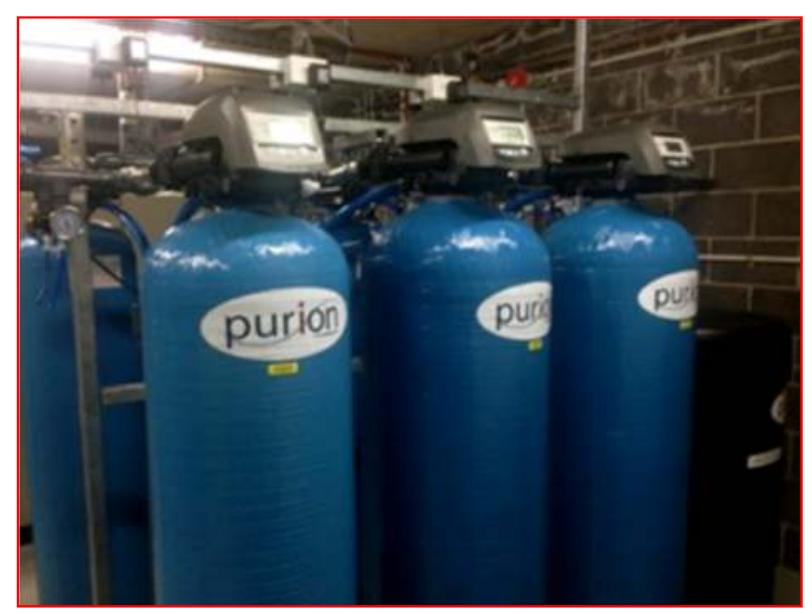

(A) 2 carbon filters, 1 softener tank and a brine tank in series.

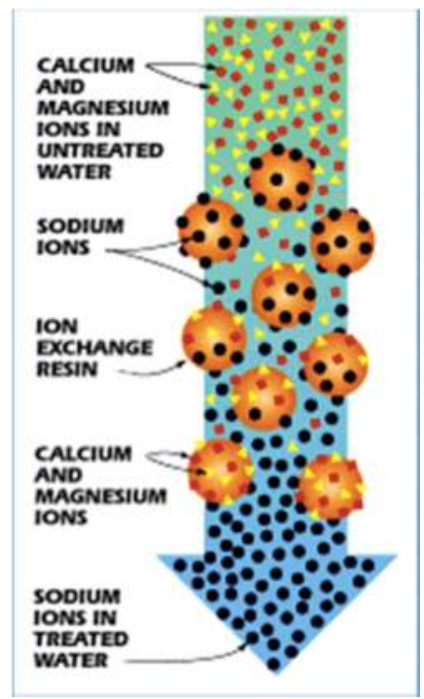

(B) Mechanism of softener function, illustrating ion exchange

Figure 4. Softeners and mechanism of action.

Large amounts of particulate matter and salts have the potential to affect the efficiency of the carbon and WRO filters. In home dialysis installations, our local experience has been that multimedia filters and softeners do not affect the water quality standards. We do not routinely use these filters in our home water setup. Our RO membranes are routinely changed approximately every 5 years and the absence of the multimedia filter and softeners has not led to early failure of the WRO. Once again this will be dependent on the quality of the feed water. 


\subsection{Activated carbon}

Activated carbon is a highly porous carbon material that is created by adding heat and steam to carbon containing products such as coal and wood. The carbon is then acid washed to clean and increase its porosity. The primary purpose of the carbon filter is to remove chlorine and its related compounds, including chloramines and halogenated organic material, like trihalomethanes (Figure 5). With regular use the carbon becomes spent with no further binding available along its large surface area.

Chloramines are derived from chlorine and ammonium and is added to drinking water, as a disinfectant as it is more stable, does not dissipate as rapidly as free chlorine and reduces the formation of chlorinated organic compounds such as trihalomethanes [10] (see section on water testing). It is important to note that the RO filter does not remove chlorine. Activated carbon is the best method of removing chloramines and is achieved by physical adsorption and chemical catalysis to its parent compounds. The adsorptive capacity of the carbon filter is determined by the contact time of the carbon with water, known as empty bed contact time (EBCT) and the Iodine number of the carbon. The iodine number of a carbon is calculated by its ability to absorb iodine per gram of carbon. The EBCT is directly proportional to the volume of carbon in the carbon tank and inversely proportional to the flow and can be exactly calculated using a formula. The larger the carbon tanks, the higher the EBCT provided the flow rate is constant.

The tanks are connected in series with the first tank providing most of the chlorine removal; hence it is usually referred to as the 'worker' tank and the second called the 'polisher'. With regular use, the absorptive sites on the carbon particles become exhausted and their efficiency declines. Conditions within the carbon tanks, especially the polisher, are ideal for bacterial proliferation in that it is chlorine deplete and contains organic matter. To increase the efficiency and prolong its lifespan, the carbons are backwashed ie 'fluffing the carbons'. This is usually performed weekly and the tanks are changed every 12 months.

Both in the home and in-centre setting, patients and staff, respectively, test the dialysis water daily prior to treatment. If chlorine is detected, dialysis is not initiated and an immediate carbon change is effected. Our center, also tests for trihalomethanes (THMs) (see section on water testing), in both the home and in centre setting. The carbons effectively remove THM's. In our experience, elevated THM levels often precede a chlorine breakthrough and are also a marker of the organic load in the water. The ISO guidelines recommend an EBCT of at least 10 minutes and a Iodine number $>900$. It also recommends that carbon be acid washed by the manufacturer and that regenerated carbon not be used [9].

\subsection{UV}

The ultra violet (UV) light emitters function to deactivate microorganisms. Exposure to UV results in damage to the nucleic acids of the cell. The ISO recommends that a minimum radiant energy dose should be 16 milliwatt-s/ $\mathrm{cm}^{2}$ and that unit replacement and maintenance should occur annually [11-13]. 


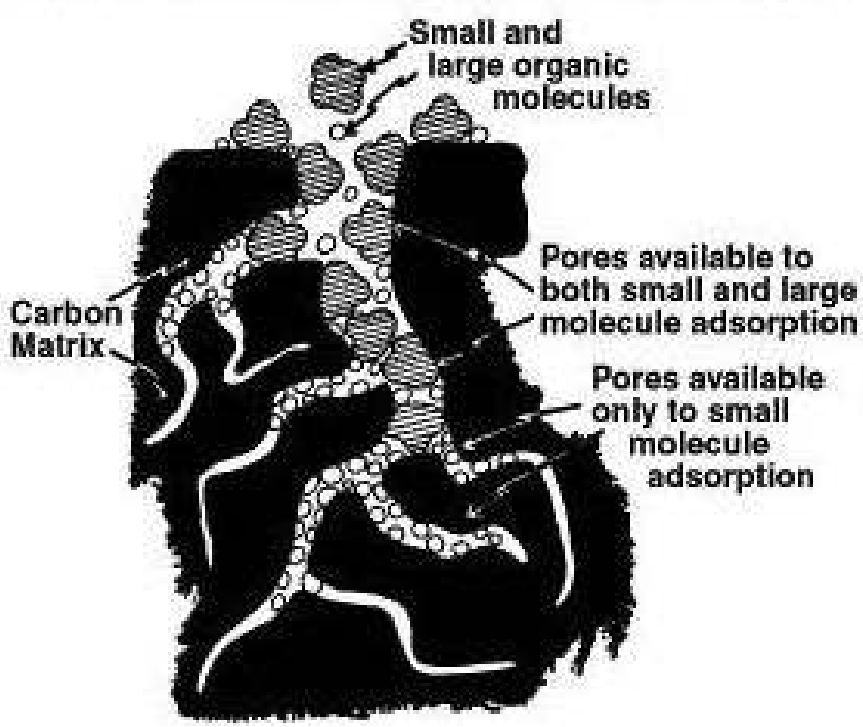

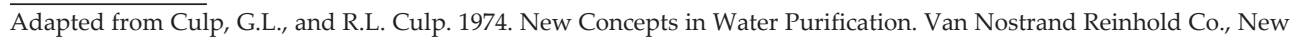
York.

Figure 5. Activated carbon particle

\subsection{De-ioniser}

Deionisers work on the principle of ion exchange to remove organic or inorganic ions from the water. Typically a mixed bed, anion and cation exchange resin would be used. These have largely been replaced by the use of reverse osmosis technology.

\subsection{Reverse osmosis}

Water reverse osmosis (WRO) units operate by pumping water, at pressure, across a semi permeable membrane, using a cross flow, membrane filtration system (Figure 6). Here a single stream of water is presented to the membrane, at which point it can either pass across the membrane as pure permeate or be "rejected" by the membrane and flow to waste. The WRO will remove metals (e.g. manganese, iron and fluoride), as well as organic molecules (e.g. bacteria). Effective and efficient operation of the WRO is proportional to the quality of feedwater; hence making the pre-treatment process obligatory to maximise the longevity of the membrane.

There are various WROs available on the market, differing in membrane type (e.g. cellulose, synthetic, composite) and membrane configuration. Typically, a polyamide, thin film composite in a spiral configuration is used in haemodialysis.. Water $\mathrm{pH}$ ideally should be between 5 and 8.5. A higher $\mathrm{pH}$ will cause the carbon filters chloramine absorption to be less effective and also reduce the efficiency of the $\mathrm{RO}$ membrane. 


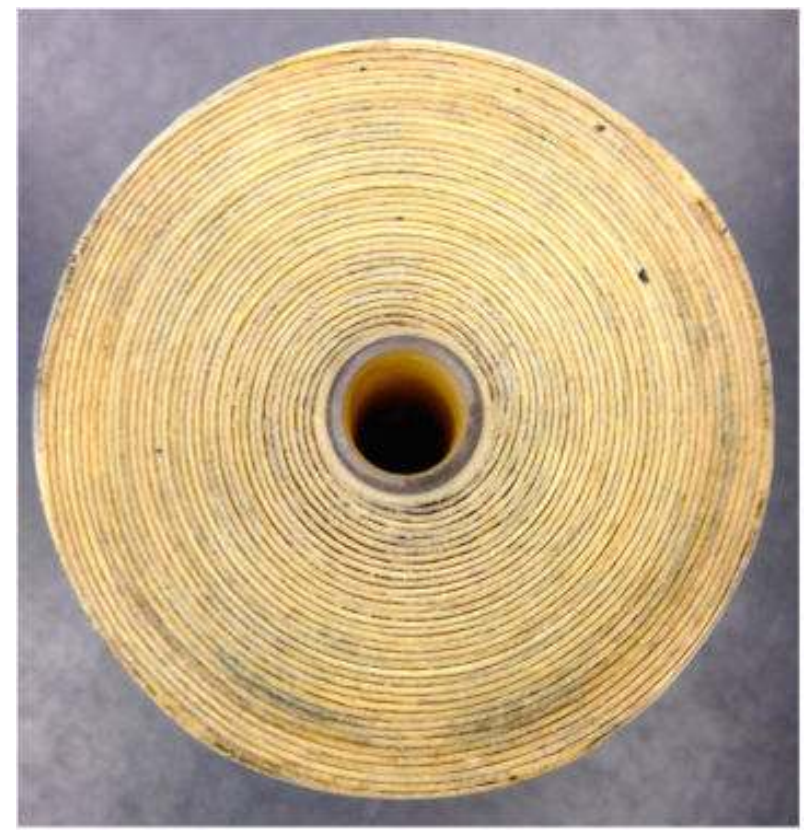

Figure 6. Used RO membrane from a home dialysis WRO machine

The WRO unit has an internal conductivity sensor and uses this to monitor the efficiency of the WRO membrane by measuring the conductivity both pre-and post-filtration and then calculating a percentage efficiency. Post membrane water usually has a conductivity of between $2-10 \mu \mathrm{Sm} / \mathrm{cm}$. The machine has programmable alarm limits, which can be adjusted by the technicians. Although our unit routinely sets the initial alarm at $50 \mu S \mathrm{~m} / \mathrm{cm}$, our technicians usually intervene if the post RO water conductivity exceeds $20 \mu \mathrm{Sm} / \mathrm{cm}$. The machine is programmed to shut down if this exceeds $150 \mu \mathrm{Sm} / \mathrm{cm}$. Measurements of RO conductivity efficiency is only a guide and not an absolute measure of suitability for dialysis, which can only be ascertained by performing a detailed water analysis.

In the home setting, portable WROs are disinfected, by the user, either using heat, weekly or chemically, twice a week. Chemical disinfection is performed using agents, such as Dialox® solution (peracetic acid $0.35 \%$, hydrogen peroxide $6.6 \%$ ). Some units use a weekly or even fortnightly disinfection schedule. The use of chemicals reduces the longevity of the RO membrane. Newer WRO's use only heat to disinfect by heating water up to $90^{\circ} \mathrm{C}$. This has the advantage of not needing to store and transport chemicals and also prevents the rare but real danger of mistakenly using the dialysis machine bleach in the WRO. Using heat disinfection WRO's also offers the unique advantage of integrated disinfection. Here the heated solution is not limited to the WRO but extends simultaneously to the HD machine, thus disinfecting the piping in between and resulting in fewer breaches in water quality. In the in-centre setting, 
the loop delivery piping connecting the WRO and the dialysis machines, is heat disinfected daily, using water heated to $85^{\circ} \mathrm{C}$ with the WRO membranes being disinfected weekly.

As the WRO is used over time, several different processes start to affect its efficiency. These 3 processes include:

- fouling - the entrapment of particles in the membrane,

- scaling - deposition of eg calcium salts and

- membrane degradation.

Hence, WROs do need to be serviced regularly. This involves calibrating the conductivity sensors, checking the pump flows, descaling, checking for leaks and sterilising the machine (see Figure 8). In the home setting, the machines first undergo a high $\mathrm{pH}$, sodium hydroxide, flush followed by a low $\mathrm{pH}$ acidic solution (e.g. a citrate based solution.) Specific practices will be dependent on whether or not softeners have been used, the quality of the feed water and manufacturer specific guidelines for servicing. The WRO membranes are usually replaced every $3-5$ years.

The ISO recommends daily monitoring of the WRO unit's instrumentation panel. This usually includes, a constant readout of the product water conductivity and percentage efficiency [9]. The purpose is to monitor and log trends and confirm that the machine is operating within the manufacturer's specifications. It also recommends repeating a laboratory water analysis when significant seasonal changes in water quality are suspected or if rejection rates change by more than $10 \%$.

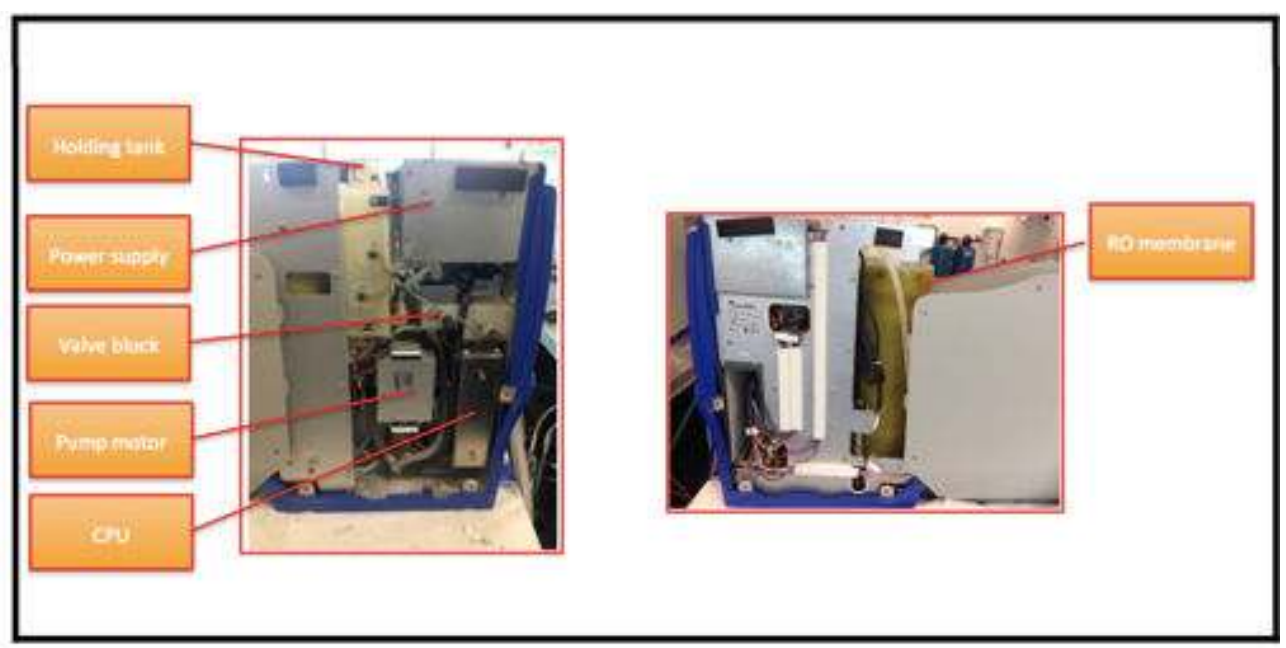

Figure 7. Portable WRO with casing removed 


\subsection{Ultra filters or endotoxin retentive filters}

Ultra filters, also known as endotoxin retentive filters, are cartridge type filters that are installed onto the dialysis machine (Figure 9). They are composed of a polysulfone material used to achieve "ultra pure" water by removing bacteria and endotoxin. This is by a process of adsorption and exclusion by particle size. Flow through the filter cartridge can be either in a "dead end" or "cross flow" configuration. In 'cross flow' mode, water flows parallel to the membrane surface with impurities "washed away" in the reject stream. In 'dead end' mode, water flows perpendicular to the membrane surface.

(A) Ultrafilter

(B) Schematic 


\subsection{Plumbing}

Only qualified plumbers registered with the local water board and with prior experience in water systems are used to plumb new installations. The main components are the filters and the piping in between. Plumbing installations including those for haemodialysis must comply with the Plumbing and drainage standard of that country.

\subsubsection{Backflow device and stop valve}

This prevents treated water, containing disinfectants, from back flowing into municipal water supply. The device cannot be tested and so are changed routinely every two years according to the manufacturer's specification.

\subsubsection{Piping, couplings, micro fittings and sealants}

The 2009 ISO guidelines recommend that piping should not contribute any chemicals eg copper, lead, zinc or chemicals. [9]. Common practice is the use of PVC (polyvinyl chloride) piping as it is non corrodible, is able to withstand high temperatures achieved during disinfection and has a smooth inner surface to prevent biofilm.

Much controversy surrounds the potential leaching of plasticizer compounds from the dialysis tubing, including the dialyser membrane and their effects on health. Two compounds in particular, Bisphenol A and phthalate diesters are known to act as 'oestrogenic disrupting chemicals' which have been shown in rodent models, to cause liver, pancreatic, thyroid and developmental abnormalities [28, 29]. Their role in human disease remains unclear. Copper piping is used only for reject water and not for the piping that supplies the WRO and the dialysis machine, as copper can leach from the piping and result in copper toxicity to the patient [14]. Brass fittings may be minimally used for certain fixtures due to the risk of leaks and blowout with plastic couplings. Particular care needs to be taken to prevent use of and contamination from adhesives, epoxy resins or bonding cements.

\subsection{Water disposal and saving - Green dialysis}

There are two grades of wastewater created from the water filtration process. The first is reject water from the WRO, which has not come into contact with the patient and second, post dialysis effluent, which is produced during the actual dialysis process. Safe disposal of dialysis effluent water poses two issues. Firstly, because dialysis fluid is in contact with blood, it is a biological waste product and theoretically may contain bacterial or viral particles from the patient. There is however no evidence that this poses a definite infective risk. In one study dialysis wastewater was analysed and compared to municipal, industry, Food and Agriculture Organization of the United Nations (FAO) and World Health Organization (WHO) standards for wastewater use for agricultural applications. Apart from an expected higher conductivity, the dialysis wastewater did not exceed FAO standards for biochemical oxygen demand or bacteria [15]. Secondly, dialysis wastewater in the home setting is diverted to sewerage, which poses a practical dilemma for patients in the rural setting, where septic tanks are used. With the large volumes of dialysis wastewater created per treatment, this could quickly overflow 
these tanks and hence there is a need to be able to accommodate this volume. Thirdly, addition of chemicals used in the disinfection process would damage the bio flora essential in the normal function of the septic system used by some patients. For these situations, the current practice is to construct an independent water disposal pit for chemically tainted water during the disinfection process whilst all other effluent water is diverted to sewerage.

There is a high percentage of reject water (approximately $65-90 \%$ ) created by the WRO. This water, created from drinking standard feed water, has already passed through, in most cases, particle filters, carbon filters, softeners or multimedia filters. Although "reject" by dialysis purity standards, it is "pre patient" and is still drinkable in some cases [16]. Although not traditional standard practice, experts in the field, especially in water shortage areas in Australia, advocate the use of water conserving practice. This entails storing and using the 'reject' water for "grey water' purposes (e.g. gardening, cleaning etc.) [16, 17]. As a rough estimate, a dialysis unit in a tertiary hospital, servicing approximately 20 dialysis beds, can reject almost 3,000,000 litres of water annually! Secondly, reject water (RW) can be recycled back into the dialysis filtration system [18]. Here the RW is pumped into a separate storage tank, which is then re-presented to the filtration system for reuse and reprocessing. This can result in up to an $80 \%$ water saving [18]. Thirdly, water saving WRO's that internally reuse RW can also result in water saving. For example, there would typically be a 3 way valve that would redirect reject water flow away from waste and back into the supply pipe. This valve would operate in short eg. 20-second cycles, alternating between waste and the supply pipe. The recirculation rate can be varied on the machines. Commonly home dialysis and in-centre WRO units use a recirculation rate of between $10 \%$ and $65 \%$.

However recirculating reject water or using the water saving feature, will increase the feed water concentration of contaminants, which will reduce the efficiency of the WRO membrane and likely reduce its lifespan. The average water conductivity in an urban area is usually $<500 \mathrm{mSm} / \mathrm{cm}$ and it is sensible in such areas to trial a higher water recirculation percentage eg $30 \%-50 \%$. Areas where feed water quality is poor with high conductivity $>1000 \mathrm{mSm} / \mathrm{cm}$ should probably not use the water saving feature to better protect the RO membrane. Ultimately, the cost and safety concerns involved in balancing water saving against membrane longevity and water quality need to be monitored. Without trialing the water saving feature, it is impossible to know where this balance lies.

\section{Additional and optional equipment}

\subsection{Cartridge filter with basic RO membrane}

These are small, under-counter-size WRO units. In remote areas where patients are supplied by borehole water, the feedwater can have high amounts of particulate matter, dissolved salts and metals (e.g. arsenic). A cheap pre-filtering system is required to return water to near drinking water standard to protect the more expensive downstream components of the filtration system. Water from rainwater and borehole supplied tanks requires a pump that provides pressures between $300-500 \mathrm{Kpa}$ as these filters operate on line pressure. The filter 
typically has a 3 stage system that involves a carbon prefilter cartridge leading into a RO cartridge. Typically the cartridges are changed every 6 months, although this is variable depending on the feedwater quality. When the reject rate of water starts to increase (i.e. less water per minute of treated water is produced), then the cartridges are changed sooner. Typically patients will notice that the storage tank takes longer to fill alerting them that an earlier change is necessary.

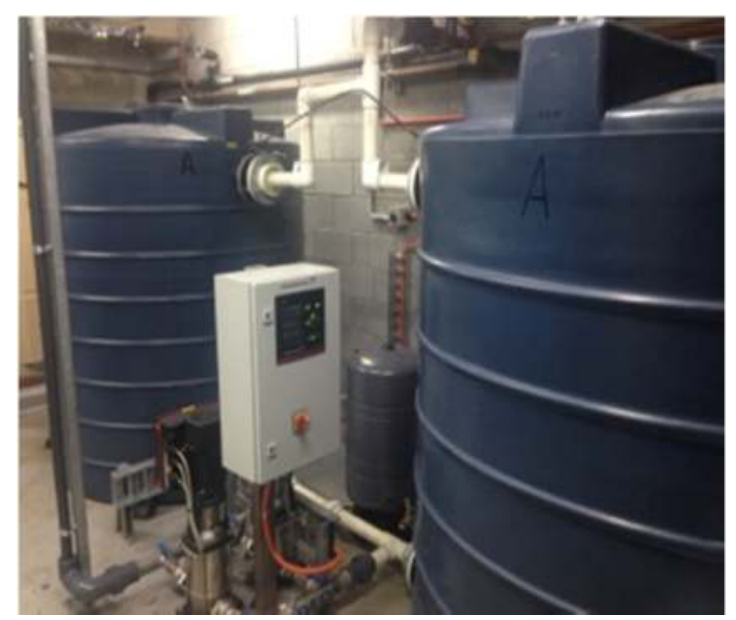

A) Two 3000L holding tanks to provide an uninterrupted water supply in case of emergency. Note also the booster pumps in the centre. These ensure an inlet pressure of at least $550 \mathrm{Kpa}$

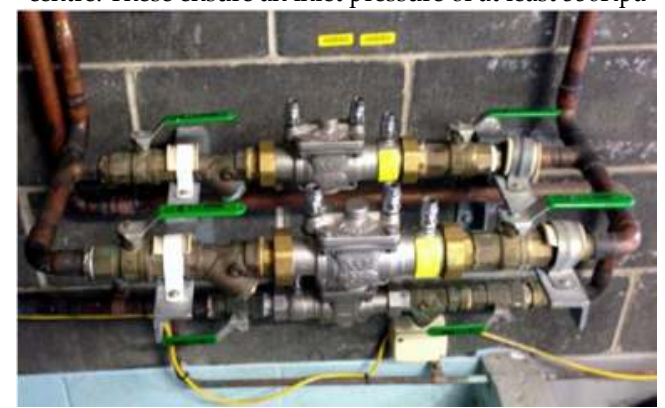

(B) A backflow device.

Figure 9. Holding tanks with booster pumps and back flow preventor

\subsection{Water temperature regulators}

As blood is passed through a dialysis circuit, heat is radiated to the cooler ambient temperature and then is brought into contact with dialysis water. The temperature of this water may have significant seasonal or diurnal variation. Dialysis machines are capable of heating but not 
cooling dialysis water to the required temperature. Feed water less than 10 degrees Celsius and greater than 30 degrees would require temperature adjustment. Feed water temperature also affects the integrity of the $\mathrm{RO}$ and particle filters, which have a maximum operating temperature set by the manufacturer, usually less than 35 degrees Celsius. In most units the temperature of dialysis water is typically $35^{\circ} \mathrm{C}$. A high dialysate temperature can result in haemolysis [19]. If feed water temperature is outside the recommended range then water temperature will need to be adjusted. This is usually not required in more temperate climates.

\subsection{Booster pumps}

When feedwater originates from rainwater or borehole, it is stored in a tank. A booster pump is necessary to pump water to the filtration system (Figure 11). Some homes especially older ones may have low mains water pressure. This may be due to low supply pressure from the municipality, corrosion or faulty pressure restrictors. If not correctable then such homes may also require a booster pump. This must be sufficient to meet the minimum pressure requirements of the RO filter, which is typically between 1 to 8 bars.

\subsection{Iron removal units}

In some circumstances high iron content in the feedwater may necessitate an independent iron removal system. A dedicated iron filter (e.g. BIRM@ Clack Corporation, Wisconsin 53598-0500 USA) is available. The ISO does not specify a level for iron in dialysis water but does recognise that it may foul downstream filters [9].

\section{Water quality testing}

The water purification system is a multiple layer system designed to progressively purify water at each step. The resulting dialysis water needs to meet minimum criteria for chemical and microbiological characteristics. These criteria form the basis of the definition for standard quality and ultrapure quality dialysis water. There are several available guidelines specifying the minimum allowable standards for water quality. (eg U.S. Association for the Advancement of Medical Instrumentation (AAMI) and the European best practice guidelines (EBPG). The ISO (international organisation for standardisation) is an international collaboration of national standard bodies (ISO member bodies). Minimum water testing parameters from the ISO are summarised below. The ISO recommends at least annual testing for chemical contaminants and quarterly testing for microbiological contaminants (Table 2) [9]. Ultimately a schedule of water testing must achieve two goals. Firstly, testing must ensure that a high quality of dialysis water is being delivered at the end of the filtration process. Perturbations in feed water quality and breakthrough in upstream filters do not usually result in fouling of the dialysis water, as there is a fair degree of redundancy built into each filter. Hence, even if, for example, a post-WRO sample reveals an elevated bacterial load, a well maintained further downstream ultrafilter should still prevent this exposure to the patient. Secondly, testing at different points in the circuit enables troubleshooting and localization of the problem area. As 
in the example above, the problem would be proximal to the WRO testing port and hence the carbon filters would be backwashed and the RO disinfected. A suggested schedule for water testing frequency in the home environment in outlined below. (see Table 3).

There are 4 main points of water testing. (see table 3 and Figure 2). Water samples are best sent to an experienced testing facility for all water analyses.

\begin{tabular}{|c|c|c|c|c|}
\hline & \begin{tabular}{|l|} 
Drinking \\
water \\
standards: \\
$\mathrm{mg} / \mathrm{l}^{10}$ \\
\end{tabular} & $\begin{array}{l}\text { Standard } \\
\text { dialysis } \\
\text { water } \\
\mathrm{mg} / 1 \mathrm{l}^{112} \\
\end{array}$ & $\begin{array}{l}\text { Ultrapure dialysis } \\
\text { fluid }\end{array}$ & $\begin{array}{l}\text { Symptoms and disease } \\
\text { associations: }\end{array}$ \\
\hline \multicolumn{5}{|l|}{ Contaminant: } \\
\hline Aluminium & 0.1 & 0.01 & & Anaemia, neuropathy, bone disease \\
\hline Total chlorine & 5 & 0.1 & & Haemolysis \\
\hline Chloramine $^{13}$ & 3 & 0.1 & & Haemolysis \\
\hline Copper & 2 & 0.1 & & Haemolysis \\
\hline Fluoride & 1.5 & 0.2 & & Bone disease \\
\hline Lead & 0.01 & 0.005 & & Haemolysis, neuropathy, gout ${ }^{14}$ \\
\hline Nitrate & $50-100$ & 2 & & Hypotension, Haemolysis \\
\hline Sulphate & 250 & 100 & & Acidosis \\
\hline Zinc & 3 & 0.1 & & Anaemia \\
\hline Antimony & 0.003 & 0.006 & & \\
\hline Arsenic & 0.01 & 0.005 & & Encephalopathy, cancer ${ }^{15,16}$ \\
\hline Barium & 2 & 0.1 & & \\
\hline Beryllium & 0.06 & 0.0004 & & \\
\hline Cadmium & 0.002 & 0.001 & & \\
\hline Chromium & 0.05 & 0.014 & & \\
\hline Mercury & 0.001 & 0.0002 & & \\
\hline Selenium & 0.01 & 0.09 & & \\
\hline Silver & 0.1 & 0.005 & & \\
\hline Thallium & NS & 0.002 & & \\
\hline Copper & 2 & & & Anaemia \\
\hline Calcium & 200 & $2(0.05)$ & & Muscle weakness \\
\hline Magnesium & $\operatorname{TDS}(600)$ & $4(0.15)$ & & Muscle weakness \\
\hline Sodium & 180 & 70 & & \\
\hline Potassium & TDS & 8 & & \\
\hline \multicolumn{5}{|l|}{$\begin{array}{l}\text { Microbiological } \\
\text { criteria: }\end{array}$} \\
\hline $\begin{array}{l}\text { Microbial count } \\
(\text { CFU } / \mathrm{ml})^{11}\end{array}$ & $\begin{array}{l}\text { Individual } \\
\text { bacterial } \\
\text { levels, eg } \\
\text { Ecoli }\end{array}$ & $\begin{array}{l}<\quad 100 \\
\mathrm{CFU} / \mathrm{ml}\end{array}$ & $<0.1 \mathrm{CFU} / \mathrm{ml}^{(1)}$ & Hypotension, inflammation \\
\hline $\begin{array}{l}\text { Endotoxin } \\
\text { Concentration } \\
\text { EU/ml }\end{array}$ & NS & $\begin{array}{l}<\quad 0,25 \\
\mathrm{EU} / \mathrm{ml}\end{array}$ & $<0.03 \mathrm{EU} / \mathrm{ml}$ & Hypotension, inflammation \\
\hline \multicolumn{5}{|c|}{$\begin{array}{l}\text { 1. ISO } 2009 \text { standards for haemodialysis water recommend Ultra pure water for routine dialysis, defined as a } \\
\text { microbial count }<0,1 \text { cfu/ml and an endotoxin concentration }<0.03 \mathrm{EU} / \mathrm{ml} \\
\text { 2. Total dissolved solids (TDS) consist of inorganic salts and small amounts of organic matter that are } \\
\text { dissolved in water. The palatability of drinking water has been rated according to TDS concentrations. } \\
\text { High TDS values, apart from taste, may also be associated with excessive scaling in pipes, fittings and } \\
\text { household appliances }\end{array}$} \\
\hline
\end{tabular}

Table 2. ISO recommendations for water quality in dialysis water [20] 


\begin{tabular}{|c|c|c|c|c|c|c|}
\hline $\begin{array}{l}\text { Collection } \\
\text { point }\end{array}$ & $\begin{array}{l}\text { Bacteria } \\
\text { and Endo } \\
\text { count }\end{array}$ & Pesticides $^{5}$ & THM & $\begin{array}{l}\text { Heavy } \\
\text { metals }\end{array}$ & $\begin{array}{l}\text { Anions, } \\
\text { cations, pH, } \\
\text { conductivity: }\end{array}$ & $\begin{array}{l}\text { Standard }{ }^{3} \\
\text { water } \\
\text { analysis: }\end{array}$ \\
\hline $\begin{array}{l}1-\text { Feed } \\
\text { water }\end{array}$ & $\begin{array}{l}\text { Rural: } 3-6 \\
\text { monthly \& } \\
\text { pre initial } \\
\text { install }\end{array}$ & $\begin{array}{l}\text { As } \\
\text { requested }^{4}\end{array}$ & & $\begin{array}{l}\text { As } \\
\text { requested }\end{array}$ & & $\begin{array}{l}6-12 \\
\text { monthly } \\
\text { rural }\end{array}$ \\
\hline $\begin{array}{l}2-\text { Inter } \\
\text { carbon }\end{array}$ & & & 3 monthly ${ }^{2}$ & & & \\
\hline 3 - Post RO & $\begin{array}{l}3 \text { monthly } \\
\text { (monthly } \mathrm{HDF} \\
\text { until stable) }\end{array}$ & $\begin{array}{l}\text { Annually } \\
\text { (Rural } 3-6 \\
\text { monthly) }\end{array}$ & & $\begin{array}{l}\text { Annually } \\
\text { (Rural } 3-6 \\
\text { monthly) }\end{array}$ & $\begin{array}{l}\text { Annually } \\
\text { (Rural 3 } 3 \text { - } 6 \\
\text { monthly) }\end{array}$ & \\
\hline $\begin{array}{l}4-\mathrm{HD} \\
\text { machine }\end{array}$ & $\begin{array}{l}3 \text { monthly } \\
\text { (monthly HDF } \\
\text { until stable) }\end{array}$ & & & & & \\
\hline $\begin{array}{lr}\text { 1. } & \text { Nos } 1-4 \\
\text { 2. } & \text { Chlorine } \\
& \text { performed by } \\
\text { 3. } & \text { Standard } \\
\text { 4. } & \text { Colony f } \\
\text { 5. } & \text { Pesticide } \\
& \text { areas. In addit }\end{array}$ & $\begin{array}{l}\text { correspond to schem } \\
\text { esting occurs routine } \\
\text { vater testing staff } \\
\text { vater analysis include } \\
\text { rming units and endo } \\
\text { testing frequency is } \\
\text { on seasonal variation }\end{array}$ & $\begin{array}{l}\text { tic representation of } \\
\text { y before each treatm } \\
\text { s pH, conductivity, to } \\
\text { toxin count } \\
\text { also dependent on an } \\
\text { are also considered. }\end{array}$ & $\begin{array}{l}\text { vater circuit } \\
\text { nt using a dipstick- } \\
\text { rbidity (see below sa } \\
\text { a, eg farmlands and } \\
\text { Generally } 4 / y r\end{array}$ & $\begin{array}{l}\text { olour chart based syst } \\
\text { aple report) } \\
\text { rural areas are tested }\end{array}$ & $\begin{array}{l}\text { em. } 3 \text { monthly, total chl } \\
\text { more frequently compa }\end{array}$ & $\begin{array}{l}\text { orine testing is also } \\
\text { red to metropolitan }\end{array}$ \\
\hline
\end{tabular}

Table 3. Schedule for water testing

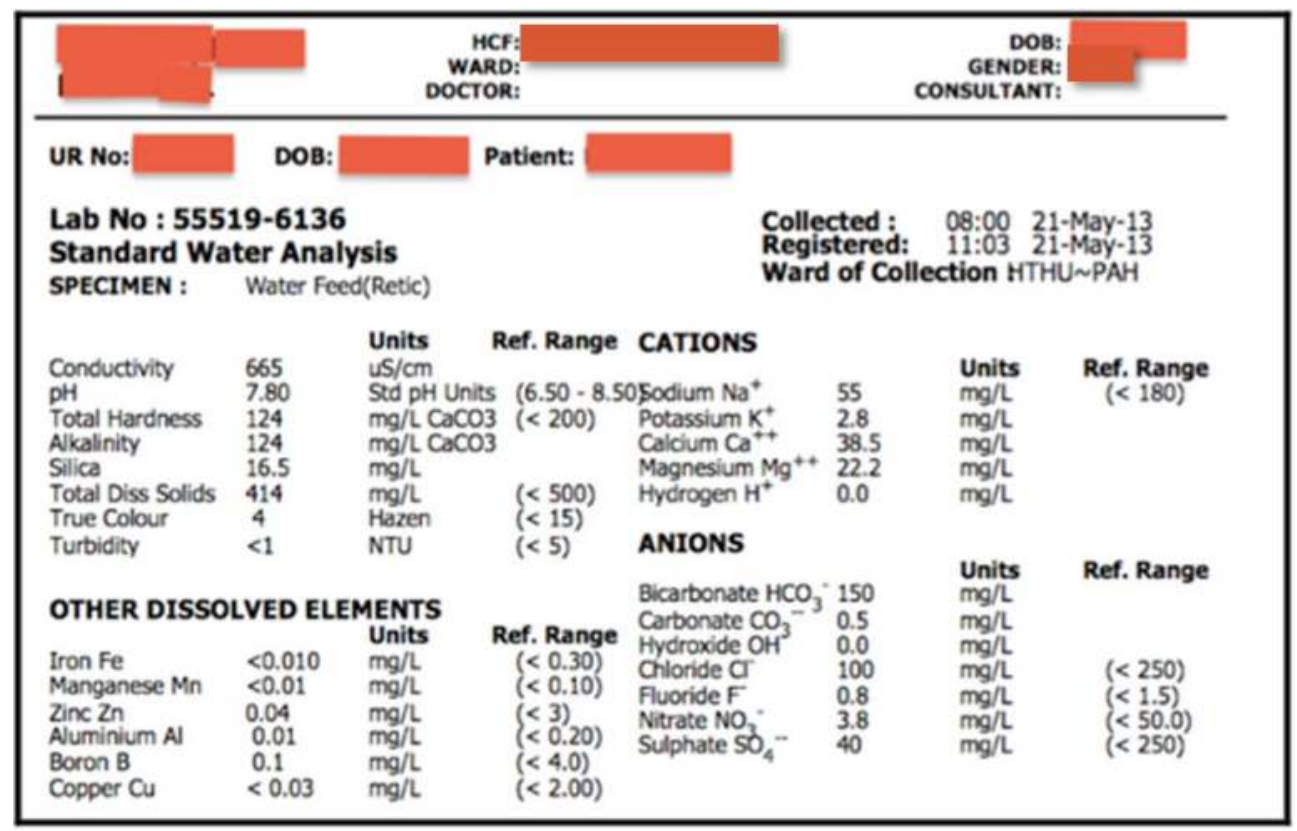

Figure 10. Example of a standard water analysis report 


\subsection{Chemical testing}

Chlorine is a strong oxidising agent used in the disinfection of municipality drinking water. Inadequately treated dialysis water can result in significant patient exposure to chlorine. Here ferrous iron $\left(\mathrm{Fe}^{2+}\right)$ in haemoglobin is converted ferric iron $\left(\mathrm{Fe}^{3+}\right)$ resulting in the formation of methaemoglobin, haemolysis and anaemia [21, 22]. Due to its toxic nature and abundance, testing for chlorine occurs twice daily in dialysis units. This is performed using indicator test strips or testing tablets, which cause a colour change in the presence of chlorine. Electronic chlorimeters are also used and these are serviced regularly. In the home setting, patients are trained to perform a chlorine check before any dialysis session is initiated. In addition, trained water technicians visiting the home for maintenance reasons, also check chlorine levels. Chlorine testing is not routinely performed in the lab, as the samples need to be tested within 4 hours of collection due to the instability of the chlorinated compounds.

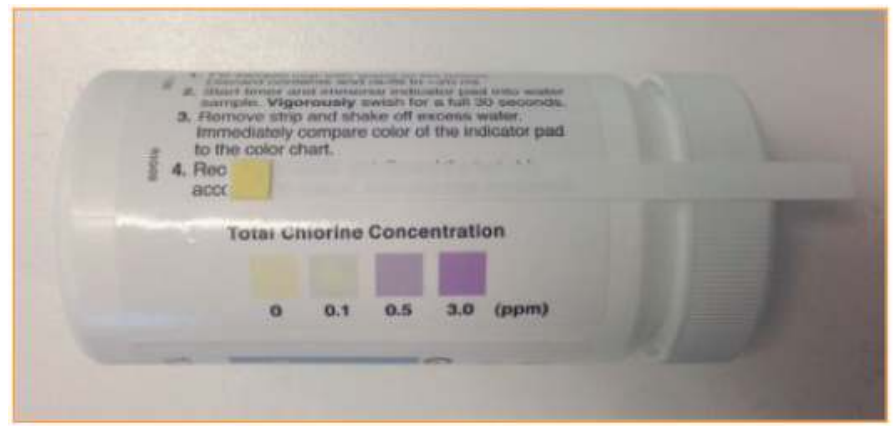

Figure 11. Colour based chlorine test strips

Aluminium has been associated with renal bone disease, anaemia and dementia [1). Although measurable, serum levels are not a good marker of organ concentration and proper water treatment is the only preventative measure possible. Other disease associations with contaminants are summarised in the table 3. Gas or liquid chromatography with mass spectrometry are powerful tools used in analytical chemistry to separate, identify and quantify compounds in a liquid and can also be used as a screening test to detect contaminants in water samples. It is important to realise that chemicals detected in ultrapure samples tested at the end of the circuit may have originated not only from the feed water but also the plumbing, membranes or heated plastics, within the circuit.

Trihalomethanes levels are not specified in the ISO guidelines but are part of routine testing at certain facilities. (also see carbon filters above). These are a group of organic chemicals that are formed by the water disinfection process, by the reaction of chlorine with organic matter eg decaying plant and vegetable matter. Exposure to trihalomethanes in drinking water has been associated with liver damage, carcinogenicity and adverse reproductive effects [10, 23, 24]. Our institution currently tests for THM's in our water circuit between carbon tanks. The Australian drinking water guideline specifies a maximum concentration of trihalomethanes 
not greater than $0.25 \mathrm{~g} / 1$ [250ppb) [25]. The EPA (Environmental protection agency) in the USA specifies a lower limit of $0.08 \mathrm{~g} / \mathrm{l}$ ie 80 parts per billion (ppb). There is no specification for THM levels in dialysis water. In Australia, dialysis facilities use a level of 1/10th of the EPA drinking water guideline. It is believed that the presence of THM's greater than $8 \mathrm{ppb}$ usually heralds the imminent breakthrough of chloramines and/or chlorine post carbon. Levels greater than $8 \mathrm{ppb}$ trigger an action protocol resulting in swapping out and rotation of the carbon tanks, which can be performed on a semi elective basis.

Standard quality dialysis water has minimum microbiological and contaminant concentrations, defined by the ISO [9). (see table 3). Ultrapure water has more stringent microbiological criteria specifying a lower bacterial load and endotoxin concentration. Although ultrapure water can now be easily produced with the regular use of ultrafilters, the more stringent microbiological criteria make testing a more involved and lengthy process for instance longer culture times. Microbiological testing involves testing for bacteria and endotoxin and is discussed further below.

\subsection{Microbiological testing}

Microbiological analysis involves testing for bacteria and endotoxins. Endotoxins are the lipopolysaccharide layer of the gram-negative bacterial cell walls. However it is worth noting that bacterial culture and endotoxin testing do not exclude all possibility of bacterial contamination. For example, they do not detect gram-positive cell wall components e.g. peptidoglycan, or bacterial fragments, unculturable organisms or dead bacteria [26], all of which may still elicit an inflammatory response when introduced into the blood stream. The clinical relevance of this is unknown.

Various factors can affect the ability of bacteria to be cultured. These include the type of culture medium, length of incubation and temperature, all of which are specified in the ISO guideline [9). The method of collection is also standardized by the ISO. Sampling ports are cleaned with alcohol, connectors soaked in ethanol to prevent contamination and water is allowed to run for the first 30 seconds. The [9) guidelines also recommend that samples be assayed within 4 hours of collection. The guideline recommends that this time can be extended by refrigeration, up to $24 \mathrm{rs}$. However this is not easily achievable especially considering the remote location of many of the home dialysis patients.

Potential organisms that contaminate the water circuit are accustomed to a nutrient poor environment hence necessitating special consideration. These include using a nutrient poor culture medium (e.g. Reasoners agar [R2A]), the use of membrane filtration for low colony count detection, an incubation temperature of between 17 and 23 degrees Celsius and an incubation period of 7 days [27]. The concentration of contaminants at which action should be instituted is set at $50 \%$ of the maximum allowable level; that is intervention is required when $50 \%$ of the allowed maximum is reached.

Endotoxin testing is performed using the Limulus amoebocyte lysate (LAL) assay. Here serum (amebocytes) removed from the horseshoe crab (limulus) is exposed to endotoxin. This activates a proteolytic cascade in the crab serum resulting in the formation of a gel like 
substance. An artificial substrate added to the lysate is also proteolytically cleaved and the liberated protein can be measured by its ability to absorb light, which is the basis of the chromogenic test kits. The test can also be quantified by its ability to form a clot or produce turbidity. It is important to note that the LAL assay does not detect endotoxin < $8000 \mathrm{Da}$.

\section{Unique environments eg rural home setup}

Home dialysis has resulted in a multitude of benefits for patients. Most importantly with convenience, independence and improvement in biochemical and likely mortality figures. The availability of electricity and running water should not disparage patient's eligibility for dialysis. In Australia the possibility of solar powered dialysis has been shown to be a feasible option, if not completely then to significantly offset the power costs of dialysis [17]. Similarly the lack of running water should also not be a limiting factor. Illustrated below is an example of how home dialysis became a possibility for a patient living on a farm over $200 \mathrm{~km}$ from the nearest major city.

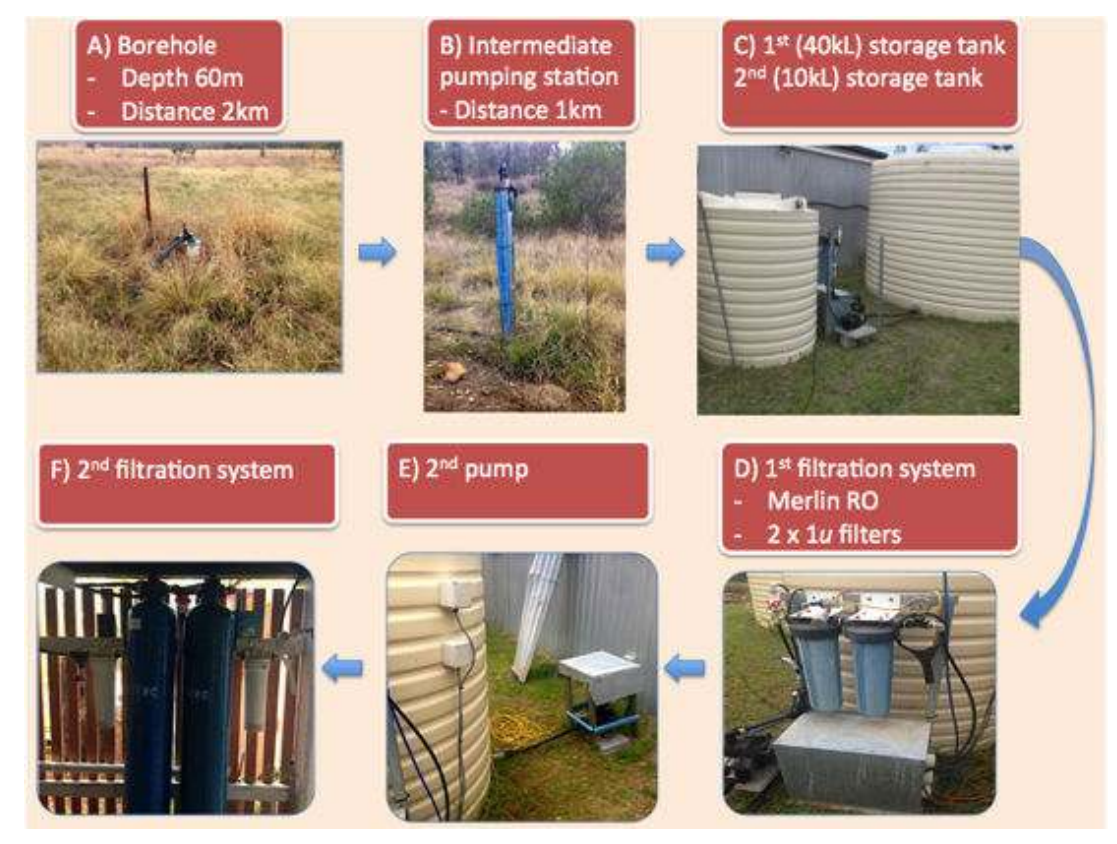

Figure 12. An Example of a rural home water treatment setup: (A) The borehole is approximately $2 \mathrm{~km}$ from the patient's residence and is determined by the geology of the area. (B) An intermediate pumping station operated using air pressure. (C) Storage tanks are continually replenished from the bore to ensure an uninterrupted water supply. (D) A basic pre filtration cartridge filter (located in the silver casing) and two micron filters pre treat the water (E) A second pump located approximately $100 \mathrm{~m}$ from the patients residence $(\mathrm{F}) \mathrm{A}$ second set of micron filters and carbon tanks. This is located underneath the patients home and feeds directly to dialysis machine inside the bedroom. 


\section{Special situations; floods and droughts}

Floods are often devastating natural disasters that result in extensive disruption of transport, communication and power supply networks, as well as industrial, farming, business and personal property damage. Table 4 summarises some of the important implications for haemodialysis patients. Experience from previous natural disasters has highlighted the importance of dialysis units having a practiced disaster management plan to manage these situations. During the 2005 Hurricane Katrina disaster, 94 dialysis centres closed for at least one week affecting close to 6000 patients [30,31]. The national kidney foundation provides a useful guide for disaster planning for people with chronic kidney disease. It includes useful information for patients such as fluid and dietary advice, including salt, potassium and water restriction, medical record management, dialysis rationing and medication supply [32].

\begin{tabular}{ll}
\hline Problem: & Proposed Action: \\
\hline Water contamination: & \\
\hline Increased particulate matter from surface run off & Increase capacity and schedule of micron filter change \\
\hline Increased pesticides/herbicides/organic contaminants & $\begin{array}{l}\text { Consider increasing EBCT, increasing capacity and schedule of } \\
\text { carbon change }\end{array}$ \\
\hline Increased chlorine load from municipality & As above and ensure regular chlorine testing \\
\hline Increased ionic/dissolved solute load & $\begin{array}{l}\text { Monitor WRO conductivity and reject rates. Consider } \\
\text { increasing disinfection schedule }\end{array}$ \\
\hline Variations in water supply and pressure & $\begin{array}{l}\text { Liaise with local water authority and ensure appropriate } \\
\text { capacity reservoir tanks }\end{array}$ \\
\hline Power disruptions & Backup generators \\
\hline EBCT: Empty bed contact time & \\
\hline
\end{tabular}

Table 4. Problems associated with flooding

Water is clearly a precious resource. Unfortunately large volumes of reject water are created for the provision of dialysis. (See Water disposal and saving-green dialysis). Drought prone areas should consider water recycling, water saving WRO's and rainwater collection tanks to conserve water. Close liaison with the local water authority regarding supply rationing and trucked water is imperative.

\section{Conclusion}

High volumes of ultrapure water are required for safe and effective haemodialysis. A sequential and progressive water purification system ensures that this is delivered safely to the patient. With proper maintenance and monitoring of these systems many of the incidents of the past can be avoided. With the increased uptake of home dialysis therapies the need for similarly robust systems is necessary. Home dialysis differs in that home patients have longer 
dialysis hours and are exposed to more water. Water systems are also used in different areas with differing feed water quality and machines are left unused for periods of up to 48 hours. These factors increase the risk of exposure to chemical and microbial contaminants.

Important factors that need to be considered in the management of a dialysis water treatment system, both in the home and in-centre include: the quality of the feed water, including the abundance of its supply, reliable electricity, an adequate capacity to dispose of water and a validated water-testing program. A good working relationship and communication with the local council is important; particularly in providing prior warning regarding planned maintenance, expected fluctuations in feed water quality and assistance with water subsidy schemes. In the home setting, the patient, the ultimate end user, needs to be well trained not only to perform their dialysis properly but also regarding maintenance and testing of the water system. Failure to regularly backwash carbons, test for chlorine, change particle filters or perform scheduled disinfections will ultimately lead to failure of the water treatment system. However, the needs for maintenance routines has to be balanced against patient fatigue and ultimately poor compliance. Complex protocols and frequent changes should be avoided and any episodes of technique failure should be regarded as an indication to reinforce proper protocol.

A comprehensive water analysis is the only quantitative measure of water purity. Frequent testing would theoretically be more likely detect a breakthrough contaminant, however important considerations include cost of testing and false positives especially as a consequence of collection contamination. In addition there is a remarkable degree of redundancy built into the system. Upstream failure in the proximal part of the filtration system is extremely unlikely to breach both the RO and the ultra filters. Different institutions may vary the extent of their water treatment system, with additional or larger filters; use of deionisation, multimedia filters or duplicate ultra filters and automated systems. Ultimately this increases the cost of operation with diminishing returns in improvement of water quality.

Finally, we must retain the ability to adapt our methods and reflect on our practice. Changes in the environment, water quality standards, technology and patient needs will continue to evolve and will call in to question traditional practice, such as exhaustive and costly testing and prophylactic maintenance. Ultimately, patient safety and optimising treatment efficacy will remain a priority.

\section{Abbreviations}

WRO: Water reverse osmosis unit

HDF: Haemodiafiltration

HD: Haemodialysis

EU: Endotoxin units

RW: Reject water 


\section{Acknowledgements}

Janine Jefferies, Sally Carpenter, John Poulton.

\section{Author details}

Shyam Dheda, Carolyn Van Eps, Carmel Hawley and David W. Johnson

*Address all correspondence to: shyam.dheda@gmail.com

Department of Nephrology, Princess Alexandra hospital, Brisbane, Australia

\section{References}

[1] Malluche HH. Aluminium and bone disease in chronic renal failure. Nephrology, dialysis, transplantation : official publication of the European Dialysis and Transplant Association-European Renal Association. 2002;17 Suppl 2:21-4.

[2] Berend K, van der Voet G, Boer WH. Acute aluminum encephalopathy in a dialysis center caused by a cement mortar water distribution pipe. Kidney international. 2001;59 (2):746-53.

[3] de Oliveira RM, de los Santos CA, Antonello I, d'Avila D. Warning: an anemia outbreak due to chloramine exposure in a clean hemodialysis unit--an issue to be revisited. Renal failure. 2009;31 (1):81-3.

[4] Susantitaphong P, Riella C, Jaber BL. Effect of ultrapure dialysate on markers of inflammation, oxidative stress, nutrition and anemia parameters: a meta-analysis. Nephrology, dialysis, transplantation : official publication of the European Dialysis and Transplant Association-European Renal Association. 2013;28 (2):438-46.

[5] Penne EL, Visser L, van den Dorpel MA, van der Weerd NC, Mazairac AH, van Jaarsveld BC, et al. Microbiological quality and quality control of purified water and ultrapure dialysis fluids for online hemodiafiltration in routine clinical practice. Kidney international. 2009;76 (6):665-72.

[6] Ouseph R, Ward RA. Ultrapure dialysate for home hemodialysis? Advances in chronic kidney disease. 2007;14 (3):256-62.

[7] Ahmed W, Huygens F, Goonetilleke A, Gardner T. Real-time PCR detection of pathogenic microorganisms in roof-harvested rainwater in Southeast Queensland, Australia. Applied and environmental microbiology. 2008;74 [17]:5490-6. 
[8] Jochimsen EM, Carmichael WW, An JS, Cardo DM, Cookson ST, Holmes CE, et al. Liver failure and death after exposure to microcystins at a hemodialysis center in Brazil. The New England journal of medicine. 1998;338 [13]:873-8.

[9] ISO11663. Quality of dialysis fluid for haemodialysis and related therapies. 2009.

[10] Perez-Garcia R, Rodriguez-Benitez P. Chloramine, a sneaky contaminant of dialysate. Nephrology, dialysis, transplantation : official publication of the European Dialysis and Transplant Association-European Renal Association. 1999;14 [11]:2579-82.

[11] Hijnen WA, Beerendonk EF, Medema GJ. Inactivation credit of UV radiation for viruses, bacteria and protozoan (oo)cysts in water: a review. Water research. 2006;40 (1):3-22.

[12] ISO. ISO 13959 Water for haemodialysis and related therapies. 2009.

[13] Cutler TD, Zimmerman JJ. Ultraviolet irradiation and the mechanisms underlying its inactivation of infectious agents. Animal health research reviews / Conference of Research Workers in Animal Diseases. 2011;12 (1):15-23.

[14] Lyle WH, Payton JE, Hui M. Haemodialysis and copper fever. Lancet. 1976;1 [7973]: 1324-5.

[15] Tarrass F, Benjelloun M, Benjelloun O. Recycling wastewater after hemodialysis: an environmental analysis for alternative water sources in arid regions. American journal of kidney diseases : the official journal of the National Kidney Foundation. 2008;52 (1):154-8.

[16] Agar JW, Simmonds RE, Knight R, Somerville CA. Using water wisely: New, affordable, and essential water conservation practices for facility and home hemodialysis. Hemodialysis international International Symposium on Home Hemodialysis. 2009;13 (1):32-7.

[17] Agar JW. Conserving water in and applying solar power to haemodialysis: 'green dialysis' through wiser resource utilization. Nephrology (Carlton). 2010;15 (4):448-53.

[18] J Agar RS, JM Boddington, J Magoffin, R Hungerford, T Hinton. Water-wise home dialysis: re-using $\mathrm{r} / \mathrm{o}$ reject water but with a high conductivity, revert-to-mains manual-alarming system. Nephrology (Carlton). 2007;12:1014.

[19] Jepson R, Alonso E. Overheated dialysate: a case study and review. Nephrology nursing journal : journal of the American Nephrology Nurses' Association. 2009;36 (5):551-3.

[20] ISO. International Organization for Standardization, Water for haemodialysis and related therapies, ISO 13959 :International Organization for Standardization, Geneva. 2002.

[21] Tipple MA, Bland LA, Favero MS, Jarvis WR. Investigation of hemolytic anemia after chloramine exposure in a dialysis center. ASAIO transactions / American Society for Artificial Internal Organs. 1988;34 (4):1060. 
[22] Pyo HJ, Kwon YJ, Wee KS, Kwon SY, Lee CH, Kim S, et al. An outbreak of Heinz body positive hemolytic anemia in chronic hemodialysis patients. The Korean journal of internal medicine. 1993;8 (2):93-8.

[23] King WD, Marrett LD. Case-control study of bladder cancer and chlorination byproducts in treated water (Ontario, Canada). Cancer causes \& control : CCC. 1996;7 (6):596-604.

[24] Reif JS, Hatch MC, Bracken M, Holmes LB, Schwetz BA, Singer PC. Reproductive and developmental effects of disinfection by-products in drinking water. Environmental health perspectives. 1996;104 [10]:1056-61.

[25] NHMRC. NHMRC, NRMMC [2011] Australian Drinking Water Guidelines Paper 6 National Water Quality Management Strategy. National Health and Medical Research Council, National Resource Management Ministerial Council, Commonwealth of Australia, Canberra. 2011.

[26] Glorieux G, Neirynck N, Veys N, Vanholder R. Dialysis water and fluid purity: more than endotoxin. Nephrology, dialysis, transplantation : official publication of the European Dialysis and Transplant Association-European Renal Association. 2012;27 [11]:4010-21.

[27] van der Linde K, Lim BT, Rondeel JM, Antonissen LP, de Jong GM. Improved bacteriological surveillance of haemodialysis fluids: a comparison between Tryptic soy agar and Reasoner's 2A media. Nephrology, dialysis, transplantation : official publication of the European Dialysis and Transplant Association-European Renal Association. 1999;14 [10]:2433-7.

[28] Kanno Y, Okada H, Kobayashi T, Takenaka T, Suzuki H. Effects of endocrine disrupting substance on estrogen receptor gene transcription in dialysis patients. Therapeutic apheresis and dialysis : official peer-reviewed journal of the International Society for Apheresis, the Japanese Society for Apheresis, the Japanese Society for Dialysis Therapy. 2007;11 (4):262-5.

[29] Krieter DH, Canaud B, Lemke HD, Rodriguez A, Morgenroth A, von Appen K, et al. Bisphenol A in chronic kidney disease. Artificial organs. 2013;37 (3):283-90.

[30] Kopp JB, Ball LK, Cohen A, Kenney RJ, Lempert KD, Miller PE, et al. Kidney patient care in disasters: lessons from the hurricanes and earthquake of 2005. Clinical journal of the American Society of Nephrology : CJASN. 2007;2 (4):814-24.

[31] Johnson DW, Hayes B, Gray NA, Hawley C, Hole J, Mantha M. Renal services disaster planning: lessons learnt from the 2011 Queensland floods and North Queensland cyclone experiences. Nephrology (Carlton). 2013;18 (1):41-6.

[32] National Kidney Foundation. Planning for Emergencies: A Guide for People with Chronic Kidney Disease. 1995-2006. 
